\title{
Correction to: Energy-Aware WBAN for Health Monitoring Using Critical Data Routing (CDR)
}

\author{
Anil Kumar Sagar $^{1} \cdot$ Shivangi Singh ${ }^{1}$ (D) Avadhesh Kumar $^{1}$ \\ Published online: 30 January 2020 \\ (c) Springer Science+Business Media, LLC, part of Springer Nature 2020
}

\section{Correction to: Wireless Personal Communications https://doi.org/10.1007/s11277-020-07026-6}

In the original article, the captions to Figs. 4 and 5 were incorrect and incomplete, respectively. They should read as follows:

Fig. 4 Flowchart of the suggested CDR technique

Fig. 5 Sequencing the parameters of the routing table

Publisher's Note Springer Nature remains neutral with regard to jurisdictional claims in published maps and institutional affiliations.

The original article can be found online at https://doi.org/10.1007/s11277-020-07026-6.

Shivangi Singh

shivangisinghaaa001@gmail.com

Anil Kumar Sagar

anil.kumarsagar@galgotiasuniversity.edu.in

Avadhesh Kumar

avadheshkumar@galgotiasuniversity.edu.in

1 School of Computer Science and Engineering, Galgotias University, Greater-Noida, India 